\title{
Thyroid autoimmunity in patients with hyperprolactinemia: an observational study
}

\author{
Autoimunidade tireoidiana em pacientes com \\ hiperprolactinemia: um estudo observacional
}

Eda Demir Onal', Fatma Saglam', Muhammed Sacikara', Reyhan Ersoy' ${ }^{1}$, Bekir Cakir ${ }^{1}$

1 Yildirim Beyazit University Medical School Ataturk Teaching and Research Hospital, Department of Endocrinology and Metabolism Bilkent, Ankara, Turkey

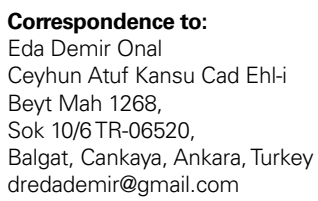

Received on June/18/2013 Accepted on July/31/2013

\begin{abstract}
Objective: To establish whether there is a relationship between hyperprolactinemia and primary thyroid disorders, focusing on patients with autoimmune features. Materials and methods: The medical records of 100 patients with hyperprolactinemia (HPRL) were retrospectively examined. Records of thyroid ultrasonography (USG), basal serum levels of thyroid stimulating hormone, circulating free thyroxine, free triiodothyronine, antithyroglobulin (anti-Tg), and antithyroperoxidase (anti-TPO) antibodies were analyzed. In 100 control subjects, matched by age and gender with HPRL patients, thyroid USG, thyroid function tests (TFTs), and autoantibody panel were obtained. Results: The median PRL in patients was $93 \mathrm{ng} / \mathrm{mL}$ (range: $37-470$ ). Twenty-five patients (25\%) and 22 controls (22\%) had positive anti-Tg and/or anti-TPO titers $(P=0.739)$. The median serum PRL was 98 (37-470) $\mathrm{ng} / \mathrm{mL}$ in patients with positive thyroid autoantibodies, and $92(40-470) \mathrm{ng} / \mathrm{mL}$ in patients who were negative $(P=0.975)$. Among the individuals with autoantibody positivity TFTs abnormalities were more frequent in HPRL patients $(60 \%$, out of 25 patients, 14 with subclinical hypothyroidism and one with hyperthyroidism) than in controls $(9.1 \%$, out of 22 patients, 2 with subclinical hyperthyroidism) $(P<0.001)$. Twenty-seven patients with HPRL and 31 controls had goiter $(27 \mathrm{vs.} 31 \%, P=0.437)$. Fortysix patients $(46 \%)$ and $50(50 \%)$ controls had one or more of the features of thyroid disorder, which were goiter, positive thyroid autoantibody, and thyroid function abnormality $(P=0.888)$. Conclusion: HPRL may be associated with more severe thyroid dysfunction in patients with thyroid autoimmunity. Arq Bras Endocrinol Metab. 2014;58(1):48-52
\end{abstract}

\section{Keywords}

Hyperprolactinemia; thyroiditis; autoimmunity; goiter

\section{RESUMO}

Objetivo: Verificar se existe uma relação entre a hiperprolactinemia e distúrbios primários da tireoide, focando em pacientes com características autoimunes. Materiais e métodos: Os prontuários de 100 pacientes com hiperprolactinemia (HPRL) foram examinados retrospectivamente. Foram analisados registros de ultrassonografia da tireoide (USG), níveis séricos basais de hormônio tireoestimulante, tiroxina livre, triiodotironina livre e anticorpos antitireoglobulina (anti-Tg) e antitireoperoxidase (anti-TPO). Foram obtidos de 100 controles, pareados por idade e sexo com pacientes com HPRL, USG, testes de função da tireoide (TFTs) e painel de autoanticorpos. Resultados: A média de PRL em pacientes foi de $93 \mathrm{ng} / \mathrm{mL}$ (variação: $37-470$ ). Vinte e cinco pacientes (25\%) e 22 controles (22\%) foram positivos para títulos de anti-Tg e/ou anti-TPO $(P=0,739)$. A mediana de PRL sérica foi de 98 (37-470) $\mathrm{ng} / \mathrm{mL}$ em pacientes positivos para autoanticorpos tiroidianos e 92 (40-470) ng/mL em pacientes negativos $(P=0,975)$. Entre os indivíduos positivos para autoanticorpos, as anormalidades da TFTs foram mais frequentes em pacientes HPRL (60\%; de 25 pacientes, 14 com hipotireoidismo subclínico e um com hipertireoidismo) do que nos controles $(9,1 \%$; de 22 pacientes, 2 com hipertireoidismo subclínico) $(P<0,001)$. Vinte e sete pacientes com HPRL e 31 controles apresentavam bócio (27 contra $31 \% ; P=0,437)$. Quarenta e seis pacientes $(46 \%)$ e $50(50 \%)$ controles tiveram uma ou mais das características de problemas de tireoide, como bócio, autoanticorpos antitireoide e anormalidades da função tiroidiana $(P=0,888)$. Conclusão: A HPRL pode estar associada à disfunção da tireoide mais grave em pacientes com autoimunidade contra a tireoide. Arq Bras Endocrinol Metab. 2014;58(1):48-52 Descritores

Hiperprolactinemia; tireoidite; autoimunidade; bócio 


\section{INTRODUCTION}

Prolactin (PRL) is a polypeptide hormone discovered more than 70 years ago to be a pituitary factor that stimulates mammary gland development and lactation $(1,2)$. It is not only produced by lactotrophic cells of the anterior pituitary gland, but also by various extrapituitary sites as neurons, prostate, decidua, mammary epithelium, skin, and immune cells (3). Over the past decade, PRL has been linked to an extended family of proteins, referred to as hematopoietic cytokines (3). The classification of PRL as a cytokine has been based on several molecular and functional evidences. First, its receptor is a member of the cytokine receptor superfamily. Second, PRL is predicted to adopt the upup-down-down four $\alpha$-helix bundle fold characteristic of hematopoietic cytokines $(4,5)$. Third, similar to well-recognized cytokines, PRL was shown to act on cells of the immune system $(6,7)$.

For the time being, the only characterized disorder related to PRL is hyperprolactinemia (HPRL), which is responsible for almost $25 \%$ of menstrual cycle disorders in women. It can also be argued that PRL should be included in the list of factors favoring the proliferation of certain tumors, e.g. breast and prostate cancer $(8,9)$. Besides these diseases linked to abnormal levels of circulating PRL, a role in the pathogenesis of autoimmune diseases has been suggested. Hyperprolactinemia has been often observed in some nonorgan-specific autoimmune diseases, such as systemic lupus erithematosus, rheumatoid artritis, systemic sclerosis, and Sjogren syndrome; moreover, it has been also described in some organ-specific autoimmune diseases, such as type 1 diabetes mellitus, Graves' diseases (GD), Hashimoto's thyroiditis (HT), Addison's disease (AD), lymphocytic hypophysitis (LYH), celiac disease (CD), and multiple sclerosis (MS) (10-19). But there is still considerable controversy concerning the true immunomodulatory role of PRL, and the subject deserves further investigation.

In this study, we attempted to establish whether there is a relationship between HPRL and primary thyroid disorders, focusing on patients with autoimmune features.

\section{MATERIALS AND METHODS}

This is a retrospective study in endocrinology outpatient clinics of a tertiary reference center in the period from January 2005 to April 2013. All HPRL cases with a records of thyroid ultrasonography (USG) and at least one measurement of basal serum thyroid stimulating hormone (TSH), circulating free thyroxine (fT4), free triiodothyronine (fT3), antithyroglobulin (anti-Tg), and/or antithyroperoxidase (anti-TPO) antibodies, were selected for inclusion. Women who were breastfeeding, using oral contraceptives, or pregnant were not enrolled. All patients participated in the study after signing an informed consent form. The local Ethics Committee of our hospital approved the study.

Venous blood samples were drawn between 8 am and 9 am from all the patients while fasting. Serum PRL, fT4, fT3, TSH, anti-Tg, and anti-TPO levels were measured by immunoassay using commercial kits. The normal ranges were: fT3: $1.8-4.6 \mathrm{pg} / \mathrm{mL}$, fT4: $0.9-1.7 \mathrm{ng} /$ dL, TSH: 0.27-4.2 uIU/mL; anti-Tg: 0-115 IU $/ \mathrm{mL}$ and anti-TPO: 0-34 IU/mL. Anti-Tg and anti-TPO titers that showed three standard deviations above the mean were considered positive. HPRL was defined as serum prolactin level $>29.9 \mathrm{ng} / \mathrm{mL}$, according to the reference assay provided by the manufacturer. The thyroid USG was performed with a Logic 200 scanner using a $7.5 \mathrm{MHz}$ linear array transducer and direct contact technique by an experienced endocrinologist. Goiter was diagnosed when the anteroposterior diameter of both lobes was $\geq 20 \mathrm{~mm}$, or when any nodule was detected. The presence of a diffuse hypoechoic pattern with or without hyperechoic lines was considered suggestive of thyroiditis. A patient was defined as having primary thyroid disorders by one or more of the following diagnostic criteria: (i) goiter, (ii) positive anti-thyroid antibodies, and/or (iii) primary thyroid function abnormalities.

A control group, matched by age and gender with HPRL patients, was used for this study. All subjects denied having known thyroid diseases or relatives with any kind of thyroid disorders. In the control group, TFTs and autoantibody panel were obtained and thyroid USG was performed.

Results were expressed as medians (range). Data between groups were analyzed by the Mann-Whitney $\mathrm{U}$ test, as appropriate for normality, and comparisons between categorical data was performed by Chi-square test with Yates' correction. Statistical analysis was performed by SPSS software (Statistical Package for the Social Sciences, version 18.0, SSPS Inc., Chicago, IL, USA). A $P$ value of less than 0.05 was considered statistically significant. 


\section{RESULTS}

Group 1 included 100 patients (mean age: $37.1 \pm 10.9$ years, range 17-63) and group 2 included 100 control subjects (mean age: $39.9 \pm 10.5$ years, range 21-68). There were 17 males (17\%) and 83 females $(83 \%)$ in each group. There were no significant differences between the two groups with respect to sex and age $(P$ $>0.05)$. The median PRL in patients was $93 \mathrm{ng} / \mathrm{mL}$ (range: 37-470). The median duration of HPRL was 3 years (range: 1-20). HPRL was caused by prolactinoma in $93(93 \%)$, antipsychotic drugs in $4(4 \%)$, and stalk compression by nonfunctional pituitary adenoma in $3(3 \%)$ patients. HPRL was successfully controlled by cabergoline in 85 (85\%), bromocriptine in 4 , and by the combination of the two agents in 11 patients.

The results of the evaluation of TFTs and thyroid autoantibody panel are shown in table 1 . The fT4 was significantly lower in group $\mathrm{l}(P=0.009)$, but the median fT4 levels was still within normal range in both groups (Table 1). The proportion of patients with subclinical hypothyroidism was significantly higher in group 1 compared with group $2(25 \%$ vs. $3 \%, P<0.001)$. There

Table 1. Thyroid function tests and autoantibody panel of the patients with hyperprolactinemia (HPRL) and control subjects

\begin{tabular}{lccc}
\hline & $\begin{array}{c}\text { Patients with } \\
\text { HPRL } \\
\text { (n= 100) }\end{array}$ & $\begin{array}{c}\text { Control } \\
(\mathbf{n = 1 0 0 )}\end{array}$ & $\boldsymbol{P}$ \\
\hline TFTs & $2.2(0.01-9.2)$ & $1.9(0.01-5.7)$ & 0.322 \\
Serum TSH & $3.2(1-4.6)$ & $3.3(2.3-4.4)$ & 0.132 \\
Serum fT3 & $1.1(0.3-1.8)$ & $1.2(0.8-1.7)$ & 0.09 \\
Serum fT4 & 73 & 95 & \\
Euthyroidism (\%) & 1 & & $<0.001$ \\
Hyperthyroidism (\%) & - & & \\
Hypothyroidism (\%) & 25 & 3 & \\
Subclinical hypothyroidism (\%) & 1 & 2 & \\
Subclinical hyperthyroidism (\%) & 16 & 10 & 0.207 \\
Anti-Tg positivity (\%) & 19 & 17 & 0.712 \\
Anti-TP0 positivity (\%) & 25 & 22 & 0.739 \\
Antibody positivity (\%) ${ }^{\mathrm{a}}$ & & & \\
Thyroid USG & 50 & 41 & \\
Normal (\%) & 27 & 31 & 0.437 \\
Goiter (\%) & 23 & 28 & \\
Thyroiditis (\%) & & & \\
\hline
\end{tabular}

TSH: thyroid stimulating hormone; fT3: free triiodothyronine; fT4: free thyroxine; anti-Tg: antithyroglobulin antibody; anti-TPO: antithyroperoxidase antibody; TFTs: thyroid function tests; USG: ultrasonography. Parametric values was expressed as means \pm S.D. Statistical significance was set at a $P$ value of $5 \%$.

Normal values: fT3: $1.8-4.6 \mathrm{pg} / \mathrm{mL}, \mathrm{fT} 4: 0.9-1.7 \mathrm{ng} / \mathrm{dL}, \mathrm{TSH}: 0.27-4.2 \mathrm{ulU} / \mathrm{mL}$.

a Positivity of anti-Tg and/or anti-TPO. were no significant differences between the two groups with respect to autoantibody positivity and the proportion of patients with ultrasonographic evidence of goiter or thyroiditis $(P>0.05)$. On the other hand, TFTs abnormalities were more frequent in HPRL patients $(60 \%$, out of 25 patients, 14 subclinical hypothyroidism and one hyperthyroidism) than in controls $(9.1 \%$, out of 22 patients, 2 subclinical hyperthyroidism) when individuals with autoantibody positivity were considered $(P$ $<0.001)$. Characteristics of $25 \mathrm{HPRL}$ patients who had evidence of thyroid autoimmunity during follow-up are shown in table 2. The median serum PRL was 98 (37$470) \mathrm{ng} / \mathrm{mL}$ in patients with positive thyroid autoantibodies and $92(40-470) \mathrm{ng} / \mathrm{mL}$ in patients who tested negative for thyroid autoantibodies $(P=0.975)$. Fortysix patients $(46 \%)$ and $50(50 \%)$ control subjects had one or more of the features of thyroid disorder, which were goiter, positive thyroid autoantibody, and thyroid function abnormality $(P=0.888)$. The median serum PRL was 98.1 (37-470) ng/mL in patients with any feature of primary thyroid disorder and 91 (40-470) ng/ $\mathrm{mL}$ in the remaining patients in group $\mathrm{l}(P=0.691)$.

\section{DISCUSSION}

Autoimmune diseases result from failure of selftolerance. A balance between positive and negative regulatory factors, both of genetic and environmental in origin, may control the susceptibility to these diseases and their progression. A shift in the balance between $\mathrm{T}$ helper $(\mathrm{Th}) 1$ and Th2 cytokine responses has been suggested to play a role in the development of autoimmune diseases. There is evidence that PRL influences the cellular arm of immune defense (20). PRL can interfere with glucocorticoid-induced maturation of Th2 lymphocytes in addition to inducing the synthesis of IFN\& and IL-2 by human leukocytes (21). PRL increases the molecules involved in dendritic cell-T cell interaction and acts on the $\mathrm{T}$ cell receptor-stimulated Thl maturation of T cells. PRL displays a predominant Thl differentiation effect on purified $\mathrm{T}$ lymphocytes (20). Data provided so far point at promotion of the development of Thl cytokine profile by PRL, although HPRL is not always associated with a Thl profile in vivo. Autoimmune diseases are often characterized by altered PRL levels, associated wtih both Thl of Th2 dominance, which suggest an immunomodulatory role of PRL (2l). 
Table 2. Characteristics of 25 patients with hyperprolactinemia who had evidence of thyroid autoimmunity during follow-up

\begin{tabular}{|c|c|c|c|c|}
\hline \multirow{2}{*}{$\frac{\text { Patient } \mathbf{n}^{\mathbf{0}} \text { (sex/age) }}{1(\mathrm{f} / 29), 2(\mathrm{f} / 42), 3(\mathrm{f} / 17)}$} & \multicolumn{2}{|c|}{$\begin{array}{l}\text { Antibody profile } \\
\text { Anti-Tg Anti-TPO }\end{array}$} & \multirow{2}{*}{$\begin{array}{c}\text { TFTs } \\
\text { Euthyroid }\end{array}$} & \multirow{2}{*}{$\begin{array}{c}\text { Thyroid USG } \\
\text { Thyroiditis }\end{array}$} \\
\hline & Pos & $\mathrm{Neg}$ & & \\
\hline $4(f / 47), 5(f / 42), 6(f / 25)$ & Pos & Pos & Subclinical hypothyroid & Thyroiditis \\
\hline 7 (f/43), 8 (f/49), 9 (f/44) & Neg & Pos & Subclinical hypothyroid & Nodular goiter \\
\hline $10(f / 35), 11(f / 17), 12(f / 40)$ & Neg & Pos & Euthyroid & Thyroiditis \\
\hline $13(f / 36), 14(f / 38), 15(f / 35)$ & Pos & Pos & Subclinical hypothyroid & Nodular goiter \\
\hline $16(f / 43), 17(f / 27)$ & Pos & Pos & Euthyroid & Thyroiditis \\
\hline $18(f / 20)$ & Pos & Pos & Hyperthyroid & Thyroiditis \\
\hline $19(f / 37)$ & Pos & Pos & Euthyroid & Nodular goiter \\
\hline $20(f / 34)$ & Neg & Pos & Subclinical hypothyroid & Normal \\
\hline $21(f / 50)$ & Neg & Pos & Subclinical hypothyroid & Thyroiditis \\
\hline $22(f / 25)$ & Pos & Neg & Subclinical hypothyroid & Thyroiditis \\
\hline $23(f / 48)$ & Pos & Neg & Euthyroid & Nodular goiter \\
\hline $24(f / 48)$ & Neg & Pos & Subclinical hypothyroid & Simple goiter \\
\hline $25(f / 49)$ & Pos & Neg & Subclinical hypothyroid & Nodular goiter \\
\hline
\end{tabular}

TFTs: thyroid function tests; f: female; m: male; anti-Tg: antithyroglobulin antibody; anti-TPO: antithyroperoxidase antibody; pos: positive; neg: negative.

There are several clinical studies that demonstrate a relationship between HPRL and autoimmune thyroid disease $(15,22-24)$. Giusti and cols. showed that the prevalence of thyroid ultrasonographic alterations including goiter and chronic thyroiditis $(30.8 \%$ vs. $15.5 \%)$ and the prevalence of autoantibodies $(29.6 \%$ vs. $14.3 \%)$ were significantly higher in HPRL than in controls (15). Another report by Ferrari and cols. reported comparable results: in a group of 82 women with HPRL, $20 \%$ had anti-Tg and $12 \%$ had anti-microsomal antibodies (22). Most patients were euthyroid in this study. In a series by Kramer and cols., positivity for any of the thyroid autoantibodies was $57.1 \%$ in untreated HPRL, $10 \%$ in HPRL on treatment, and $3.6 \%$ in the control group (23). Last, Poyraz and cols. analyzed a group of schizophrenic patients and observed that the prevalence of HPRL was significantly higher in patients positive for thyroid autoantibodies $(81 \%)$, when compared with patients negative for them $(49 \%)$. Serum levels of PRL were also significantly higher in patients with positivity for thyroid autoantibodies in that series (24). Despite the studies mentioned above, literature is still scarce with respect to primary thyroid disorders in patients with HPRL.

Anti-TG and anti-TPO are indicators of thyroid inflammation and detection of these autoantibodies is a very specific means of diagnosing autoimmune thyroid disease $(25,26)$. In this series of patients, among the individuals with autoantibody positivity TFTs abnormalities were more frequent in HPRL patients than in controls $(60 \%$ vs. $9.1 \%, P<0.001)$. This finding made us think that HPRL might be associated with a more severe thyroid inflammation leading to organ dysfunction in patients with the features of autoimmune disease. In this regard, our results agree with those of the above-mentioned studies which suggest a coexistence of autoimmune thyroid disease and HPRL $(15,22-24)$. On the other hand there was no difference between the patients and controls with respect to antithyroid autoantibody positivity (25 vs. $22 \%, P=0.739)$. And the median serum PRL was not significantly higher in patients with positive thyroid autoantibodies compared with the patients who were negative. There may be several explanations for this conflict. First, a study investigating such an association should be a prospective randomized controlled trial with a large number of participants. Second, the relevant studies should take into consideration several possible confounding factors, such as iodine status, personal or family history of autoimmune disease, certain medications (e.g., immunosuppressants, amiodarone). The above-mentioned studies and ours do not meet these two requirements $(15,22-24)$. Third, a simple 
relationship between HPRL and autoimmune diseases may not be observed on every occasion because of the complexity of the immune system. Although PRL abnormalities have been reported in immune system disorders, it has not been possible to influence the course of these diseases by manupilating PRL release in any randomized controlled trial.

The prevalence of thyroid ultrasonographic alterations including goiter and thyroiditis was not more prevalent in our patients with HPRL. Endocrinologists are more inclined to screen patients with HPRL under their care for thyroid dysfunction and thyroid nodules than general practitioners. For this reason we think that such a relationship can only be demonstrated by randomized, prospective, double-blind, placebo-controlled trials.

In conclusion, our study results did show a remarkably high prevalence of thyroid dysfunction in patients with HPRL and thyroid autoimmunity, but thyroid autoimmunity and goiter were not more frequent. Autoimmunity is a complex process and the results of similar series in the literature should be cautiously interpreted. Future prospective studies on larger populations are needed to provide irrefutable evidence to support a direct causative link between HPRL and autoimmune thyroid disease.

Disclosure: no potential conflict of interest relevant to this article was reported.

\section{REFERENCES}

1. Stricker P, Grueter R. Action du lobe ant'erieur de I'hypophyse sur la mont'ee laiteuse. C R Soc Biol. 1928;99:1978-80.

2. Riddle O, Bates RW, Dykshorn SW. The preparation, identification and assay of prolactin - a hormone of the anterior pituitary. Am J Physiol. 1933;105:191-216.

3. Ben-Jonathan N, Mershon JL, Allen DL, Steinmetz RW. Extrapituitary prolactin: distribution, regulation, functions, and clinical aspects. Endocr Rev. 1996;17(6):639-69.

4. Horseman ND, Yu-Lee LY. Transcriptional regulation by the helix bundle peptide hormones: growth hormone, prolactin, and hematopoietic cytokines. Endocr Rev. 1994;15(5):627-49.

5. GoffinV, Martial JA, Summers NL. Use of a model to understand prolactin and growth hormone specificities. Protein Eng. 1995;8(12):1215-31.

6. Nagy E, Berczi I, Wren GE, Asa SL, Kovacs K. Immunomodulation by bromocriptine. Immunopharmacology. 1983;6(3):231-43.

7. Bernton EW, Meltzer MS, Holaday JW. Suppression of macrophage activation and T-lymphocyte function in hypoprolactinemic mice. Science. 1989;239(4838):401-4.

8. Llovera M, Pichard C, Bernichtein S, Jeay S, Touraine P, Kelly PA, et al. Human prolactin (hPRL) antagonists inhibit hPRL-activated signaling pathways involved in breast cancer cell proliferation. Oncogene. 2000;19(41):4695-705.

9. Leav I, Merk FB, Lee KF, Loda M, Mandoki M, McNeal JE, et al. Prolactin receptor expression in the developing human prostate and in hyperplastic, dysplastic, and neoplastic lesions. Am J Pathol. 1999;154(3):863-70.

10. Jara LJ, Vera-Lastra O, Miranda JM, Alcala M, Alvarez-Nemegyei $\mathrm{J}$. Prolactin in human systemic lupus erythematosus. Lupus. 2001;10(10):748-56.

11. Chikanza IC, Petrou P, Chrousos G, Kingsley G, Panayi GS. Excessive and dysregulated secretion of prolactin in rheumatoid arthritis: immunopathogenetic and therapeutic implications. $\mathrm{Br} \mathrm{J}$ Rheumatol. 1993;32(6):445-8.

12. El Miedany YM, Ahmed I, Moustafa H, El Baddini M. Hyperprolactinemia in Sjogren's syndrome: a patient subset or a disease manifestation? Joint Bone Spine. 2004;71(3):203-8.

13. Neidhart M. Prolactin in autoimmune diseases. Proc Soc Exp Biol Med. 1998;217(4):408-19.

14. Li J, Teng W, Shan Z. Effects of prolactin on HLA-DR and CD40 expressions by human thyrocytes. Chin Med J. 2001;114(11):1151-6.

15. Giusti M, Foppiani L, Fazzuoli L, Molinari E, Guido R, Valenti $S$, et al. An increased prevalence of thyroid echographic and autoimmune changes in hyperprolactinemic women on therapy with dopaminergic drugs. Recenti Prog Med. 1999;90(3):147-51.

16. Lever EG, McKerron CG. Auto-immune Addison's disease associated with hyperprolactinaemia. Clin Endocrinol. 1984;21(4):451-7.

17. Thodou E, Asa SL, Kontogeorgos G, Kovacs K, Horvath E, Ezzat S. Clinical case seminar: lymphocytic hypophysitis: clinicopathological findings. J Clin Endocrinol Metab. 1995;80(8):2302-11.

18. Kapur G, Patwari AK, Narayan S, Anand VK. Serum prolactin in celiac disease. JTrop Pediatr. 2004;50(1):37-40.

19. Azar ST, Yamout B. Prolactin secretion is increased in patients with multiple sclerosis. Endocr Res. 1999;25(2):207-14.

20. Matera L, Mori M, Geuna M, Buttiglieri S, Palestro G. Prolactin in autoimmunity and antitumor defence. J Neuroimmunol. 2000;109(1):47-55.

21. Yu M, Johnson JM, Tuohy VK. Generation of autonomously pathogenic neoautoreactive $\mathrm{TH} 1$ cells during the development of the determinant spreading cascade in murine autoimmune encephalomyelitis. J Neurosci. 1996;45(4):463-70.

22. Ferrari $C$, Boghen $M$, Paracchi $A$, Rampini $P$, Raiteri $F$, Benco $R$, et al. Thyroid autoimmunity in hyperprolactinaemic disorders. Acta Endocrinol (Copenh). 1983;104(1):35-41.

23. Kramer CK, Tourinho TF, de Castro WP, da Costa Oliveira M. Association between systemic lupus erythematosus, rheumatoid arthritis, hyperprolactinemia and thyroid autoantibodies. Arch Med Res. 2005;36(1):54-8.

24. Poyraz BC, Aksoy C, Balcioğlu I. Increased incidence of autoimmune thyroiditis in patients with antipsychotic-induced hyperprolactinemia. Eur Neuropsychopharmacol. 2008;18(9):667-72.

25. Rho MH, Kim DW, Hong HP, Park YM, Kwon MJ, Jung SJ, et al. Diagnostic value of antithyroid peroxidase antibody for incidental autoimmune thyroiditis based on histopathologic results. Endocrine. 2012;42(3):647-52.

26. Erdogan M, Erdem N, Cetinkalp S, Ozgen AG, Saygılı F, Yilmaz $C$, et al. Demographic, clinical, laboratory, ultrasonographic, and cytological features of patients with Hashimoto's thyroiditis: results of a university hospital of 769 patients inTurkey. Endocrine. 2009;36(3):486-90. 